\title{
DESIGN AND MANUFACTURE CHASSIS AND BODY OF SIMPLE GOKART USING AUTOMATIC CLUTCH AND 7.5 HP ENGINE POWER N. Nazaruddin ${ }^{*}$, Dedy Masnur ${ }^{1}$, Erwin Ardiansyah ${ }^{1}$
}

\author{
${ }^{1}$ Jurusan Teknik Mesin, Fakultas Teknik, Universitas Riau \\ *e-mail: nazaruddin@eng.unri.ac.id
}

\begin{abstract}
Go-kart is a variant of a simple and small open-roof four-wheeled vehicle for motor sports. Go-kart usually races on small scale circuits. Go-kart racing is usually considered a stepping stone for motor sports that are higher and more expensive. The design of the karts is carried out by mechanical engineering students of the University of Riau based on the size of karts in general. The chassis is made of pipe with ASTM A53 pipe specifications with a tensile strength of $240 \mathrm{MPa}$ with a dimension of length of 6.22 meters, an outer diameter of $33.40 \mathrm{~mm}$ and an inner diameter of $30.02 \mathrm{~mm}$. Body building is done with fiber with a catalyst mixture ratio of 1:45. The process of painting with a ratio of primers and hardeners is $1: 4$, and clear and hardener $4: 1$. A kart with a chassis mass of $7.09 \mathrm{~kg}$ and a passenger of $70 \mathrm{~kg}$ has been produced, with dimensions of length $1100 \mathrm{~mm}$, width of $610 \mathrm{~mm}$, and distance between axes of $1050 \mathrm{~mm}$. This karting uses the 1994 Astra grand engine with 7.5 HP of power, 6000 rpm rotation and $20 \mathrm{~kg}$ mass. The transmission system used is a double automatic type.
\end{abstract}

Keywords: karts, automatic transmission, engine, chassis, fiber body.

\section{Pendahuluan}

Gokart atau balapan Kart atau karting adalah varian dari olahraga bermotor atap terbuka sederhana dan kecil, kendaraan roda empat disebut karts, gokart, atau gearbox/shifter karts tergantung pada desain[1]. Mereka biasanya berpacu di sirkuit skala kecil. Karting biasanya dianggap sebagai batu loncatan untuk olahraga motor yang lebih tinggi dan lebih mahal. Kecepatan di gokart bervariasi secara luas dan beberapa (dikenal sebagai Superkarts) dapat mencapai kecepatan melebihi $260 \mathrm{~km} / \mathrm{jam}$, sementara gokart yang dimaksudkan untuk masyarakat umum di taman hiburan mungkin terbatas pada kecepatan yang tidak lebih dari $24 \mathrm{~km} / \mathrm{jam}$. Sebuah Kf1 kart, dengan mesin 125 cc 2-langkah dan berat keseluruhan termasuk pengemudi yang terdiri dari $150 \mathrm{~kg}$ memiliki kecepatan tertinggi $137 \mathrm{~km} / \mathrm{jam}$. Dibutuhkan waktu 3 detik lebih sedikit untuk kecepatan 0-96 km/jam dengan $125 \mathrm{cc}$ shifter kart (6 gigi), dengan kecepatan tertinggi $185 \mathrm{~km} / \mathrm{jam}$ pada rangkaian panjang. Maka, topik ini diambil sebagai sarana untuk menyalurkan minat dan bakat dalam mewujudkan serta menunjang tingkat kreatif mahasiswa untuk perancangan dan pembuatan kendaraan skala kecil.

Beberapa penelitian yang telah dilakukan di lingkungan teknik mesin universitas riau untuk kendaraan sederhana diantaranya analisis statik sasis untuk Mobil Shell Eco Marathon tipe urban concept [2], perancangan dan pembuatan mekanisme dump truck[3], dan analisis kinerja sistem transmisi pada mobil hemat energi tipe hibrid[4, 5]. Kendaraan berat skala laboratorium seperti excavator $[6,7]$ juga telah dibuat sebagai unjuk kerja praktikum di lingkungan teknik mesin Universitas Riau. Analisis sasis dan sistem kemudi untuk jenis kendaraan seperti bus [8, 9] dan perancangan suspensi depan untuk prototipe compagna t-rex[10] telah ditinjau juga untuk penguatan penelitian ini.

\section{Studi Literatur}

Sasis mobil merupakan komponen utama dan sangat penting, dimana sasis ini yang menopang axle, kemudi untuk mengatur arah kendaraan, roda, ban dan rem untuk menghentikan kendaraan saat berjalan. Sistem pada sasis sangat berpengaruh langsung terhadap kenyamanan saat berkendara, stabilitas dan lain-lain. Pada bagian chasis ada beberapa hal yang harus dipahami seperti sistem rangka, sistem rem, sistem suspensi, sistem kemudi, sistem kopling, sistem transmisi, sistem diferensial dan sistem penggerak roda[11, 12].

Sasis mobil biasanya terbuat dari logam atau komposit yang bersifat memiliki kekuatan untuk menopang beban dari kendaraan. Selain itu, sasis juga berfungsi untuk menjaga agar mobil tetap rigid, kaku dan tidak mengalami bending. Beberapa jenis sasis seperti pada gambar berikut:
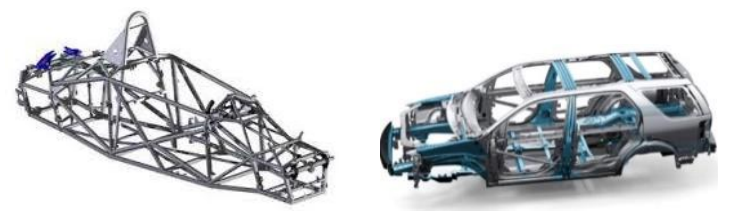

Gambar 1. Tubular Space Frame dan Monocoque 


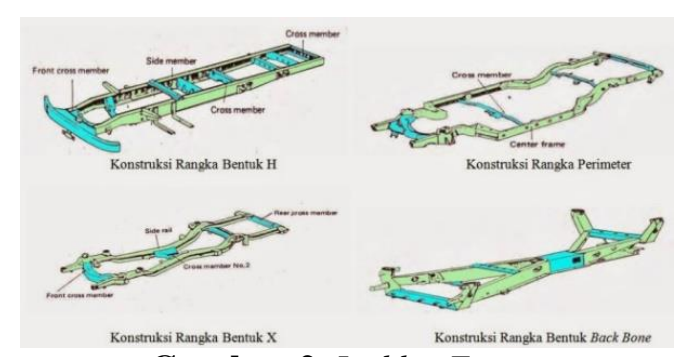

Gambar 2. Ladder Frame
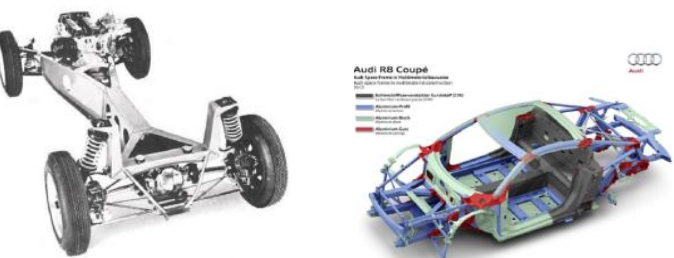

Gambar 3. Sasis Backbone dan Sasis Aluminium

\section{Metodogi Perancangan dan Pembuatan}

\subsection{Spesifikasi}

Perancangan chassis gokart ini dilakukan dengan mengacu pada referensi gokart yang telah ada, spesifikasi massa chassis gokart sebesar 7,09 kg dan massa total penumpang sebesar $70 \mathrm{~kg}$. Mesin yang digunakan adalah motor bensin 4 langkah dengan daya $7,5 \mathrm{HP}=5519$ watt.

Spesifikasi gokart lainnya:
- Panjang

$$
=1100 \mathrm{~mm}
$$

- Lebar

$$
=610 \mathrm{~mm}
$$

- Jarak antar sumbu
Spesifikasi mesin

- Jenis = Astrea Grand tahun 1994

- Daya maksimum

$$
\begin{aligned}
& =7,5 \mathrm{HP} \\
& =6000 \mathrm{rpm} \\
& =20 \mathrm{~kg}
\end{aligned}
$$

- Putaran

- Berat

Sistem transmisi

- Kopling $=$ Kopling ganda

- Transmisi = Otomatis

\subsection{Pemilihan Bahan}

Pertimbangan yang harus dilakukan dalam memilih bahan chassis[13-15]:

1. Performance yang dibutuhkan:

- Mekanikal : Kuat, tangguh, mudah dibentuk dan mudah dilas.

- Kimia : Tahan korosi.

2. Cara pembuatan chassis gokart :

Chassis gokart dibuat dengan cara di-roll dan dilas.

3. Biaya

Pembuatan chassis gokart ini menghabiskan biaya yang terjangkau. Biaya maintenance murah, karena biaya perawatanya terjangkau.

4. Berapa sering harus dilakukan pemeriksaan selama pemakaian

5. Berapa sering komponen tersebut harus dirawat Setiap selesai pengoperasian harus dilakukan perawatan dengan cara dicuci.
Tabel 1. Pemilihan Bahan

\begin{tabular}{|l|l|l|l|l|l|l|}
\hline Standar & Bahan & $\begin{array}{l}\text { Kekuatan } \\
\text { tarik }\end{array}$ & Harga & Pembuatan & Perawatan & Keterangan \\
\hline DIN & St $34-1$ & $330 \mathrm{MPa}$ & $* * * * *$ & $* * *$ & $*$ & A \\
\hline ASTM & $\begin{array}{l}\text { A } 53 / \\
\text { A } 53 \mathrm{M}\end{array}$ & $240 \mathrm{MPa}$ & $* * *$ & $* * *$ & $*$ & A \\
\hline ASTM & A 519 & $221 \mathrm{MPa}$ & $* * *$ & $* * *$ & $* * *$ & T \\
\hline JIS & G 3444 & $390 \mathrm{MPa}$ & $* * * * *$ & $* * * * *$ & $*$ & T \\
\hline JIS & G3445 & $390 \mathrm{MPa}$ & $* * * * *$ & $* * * * *$ & $*$ & T \\
\hline AISI & $\begin{array}{l}\text { AISI } \\
1020\end{array}$ & $205 \mathrm{MPa}$ & $* * *$ & $* * *$ & $* * *$ & A \\
\hline
\end{tabular}

\section{Keterangan}

A : Ada di pasaran

$\mathrm{T} \quad$ : Tidak ada di pasaran

* : : Mudah

*** $\quad$ : Sedang

$* * * * * \quad:$ Sulit

Tabel 2. Pemilihan Pipa Menurut ASTM

\begin{tabular}{|l|l|l|}
\hline Symbol & Kekuatan & Penggunaan \\
\hline A 53/ & $240 \mathrm{MPa}$ & $\begin{array}{l}\text { Spesifikasi untuk pipa, baja, Black and } \\
\text { Hot-Dipped, Zinc-Coated, Welded and } \\
\text { Seamless, mudah dilas }\end{array}$ \\
\hline A 106 & $205 \mathrm{MPa}$ & $\begin{array}{l}\text { Spesifikasi untuk pipa tanpa } \\
\text { sambungan, pipa baja karbon untuk } \\
\text { temperature tinggi }\end{array}$ \\
\hline $\begin{array}{l}\text { A 179/ } \\
\text { A 179M }\end{array}$ & $180 \mathrm{MPa}$ & $\begin{array}{l}\text { Spesikasi untuk pipa tanpa sambungan } \\
\text { Cold-Drawn, baja karbon rendah, } \\
\text { pertukaran panas dan kondensor }\end{array}$ \\
\hline $\begin{array}{l}\text { A 192/ } \\
\text { A 192M }\end{array}$ & $180 \mathrm{MPa}$ & $\begin{array}{l}\text { Spesifikasi untuk pipa tanpa } \\
\text { sambungan, pipa baja karbon } \\
\text { bertekanan tinggi untuk boiler }\end{array}$ \\
\hline $\begin{array}{l}\text { A 210/ } \\
\text { A 210M }\end{array}$ & $225 \mathrm{MPa}$ & $\begin{array}{l}\text { Spesifikasi untuk pipa baja karbon } \\
\text { medium pada boiler dan pipa-pipa } \\
\text { super panas }\end{array}$ \\
\hline A 500 & $228 \mathrm{MPa}$ & $\begin{array}{l}\text { Spesifikasi untuk Cold-Formed } \\
\text { Welded danStruktur pipa baja karbon } \\
\text { Tubing in Rounds dan Shapes }\end{array}$ \\
\hline A 519 & $221 \mathrm{MPa}$ & $\begin{array}{l}\text { Spesifikasi untuk karbon Seamless dan } \\
\text { campuran baja,bahan- bahan pipa }\end{array}$ \\
\hline $\begin{array}{l}\text { A 556/ } \\
\text { A 556 }\end{array}$ & $\begin{array}{l}\text { Spesifikasi untuk Seamless Cold- } \\
\text { Drawn Carbon Steel Feedwater Heater } \\
\text { Tubes }\end{array}$ \\
\hline
\end{tabular}

\section{Hasil dan Pembahasan}

Telah dilakukan desain sedemikian rupa sehingga mengasilkan bentuk sasis dengan distribusi titik berat seperti Gambar 4.

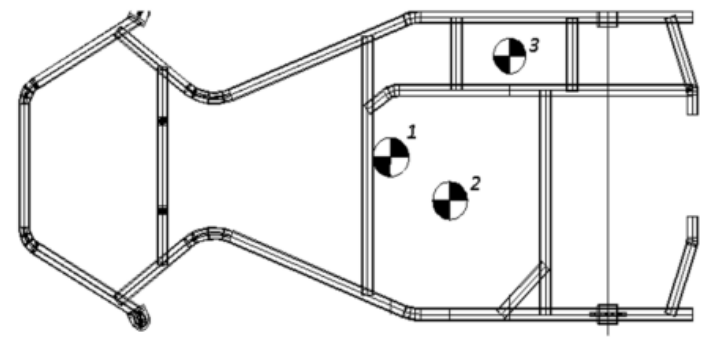

Keterangan :

1. Titik berat rangka

2. Titik berat pengemudi

3. Titik berat mesin

Gambar 4. Distribusi titik berat pada rangka sasis

Massa rangka 7,09 kg, massa pengemudi $70 \mathrm{~kg}$ dan massa engine $20 \mathrm{~kg}$ terpusat pada satu titik, seperti terlihat pada Gambar 5. 


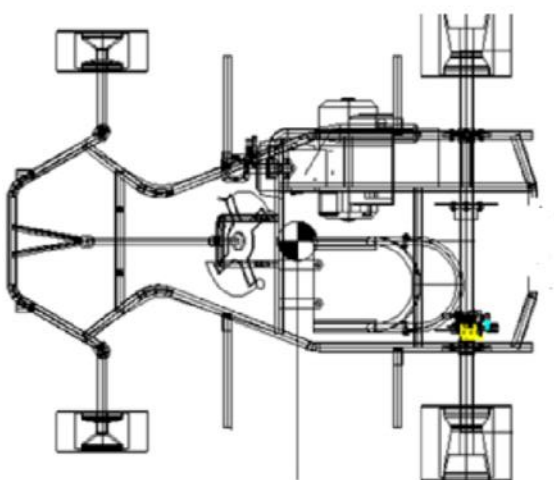

Gambar 5.Titik berat tunggal pada rangka sasis

Proses Pembuatan dan perakitan dapat dilihat pada Gambar 6 berikut ini.
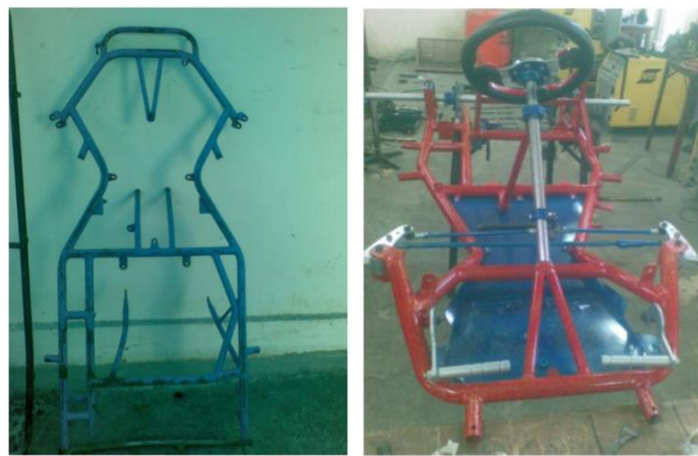

Gambar 6. Hasil Cat Dasar dan Cat Diwarnai Clear Rangka Sasis

Gambar 7 adalah flow chart perakitan sasis dan bodi gokart.
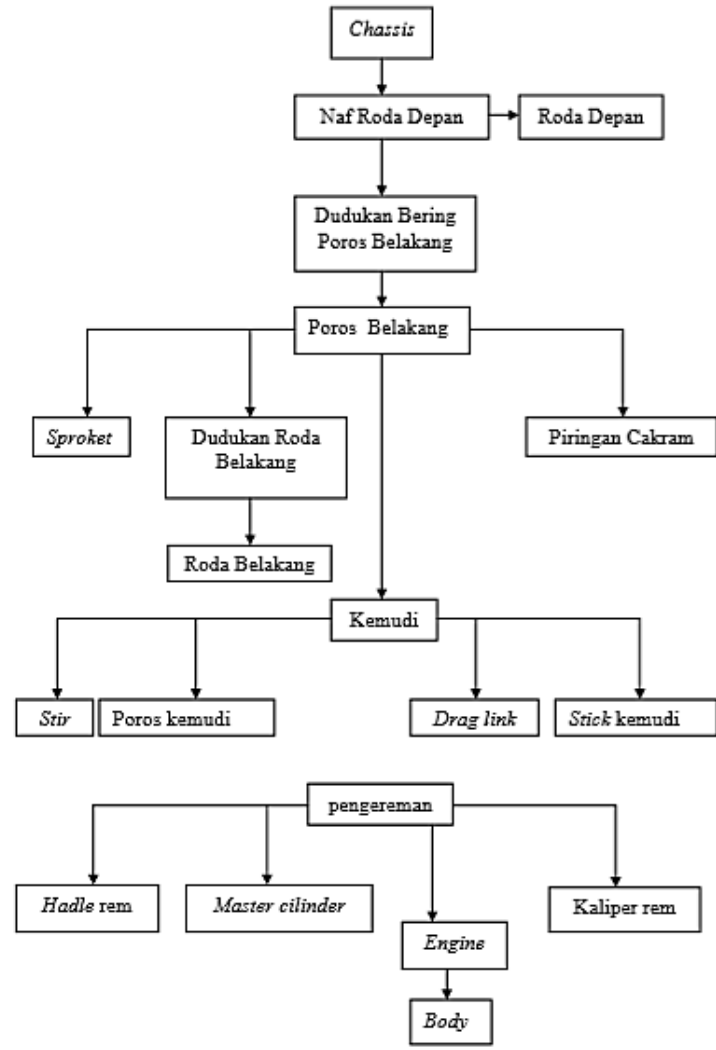

Gambar 7. Flow chart perakitan sasis dan bodi

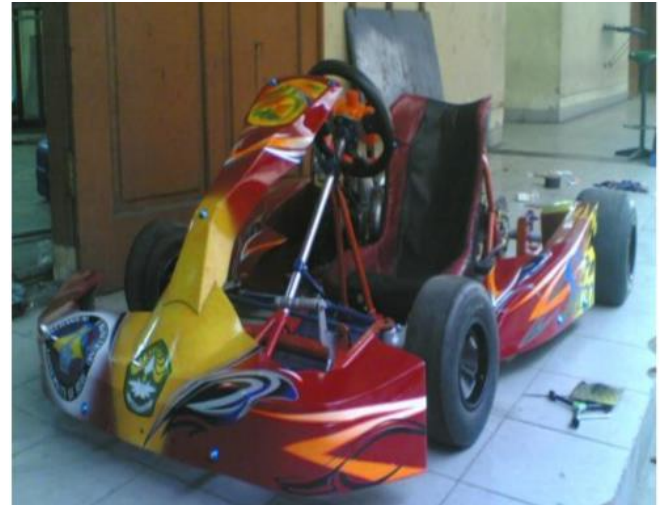

Gambar 8. Hasil Perakitan Gokart

\section{Kesimpulan}

Adapun kesimpulan yang dapat diambil dari hasil perancangan dan pembuatan gokart ini adalah :

a. Telah terbuat chassis gokart berdasarkan perancangan degan dimensi panjang 1,5 meter dan lebar 0,61 meter.

b. Pada saat menerima beban pengemudi sebesar $70 \mathrm{~kg}$ chassis mengalami deflection sebesar $1,21 \mathrm{~mm}$

c. Untuk pembuatan body dengan menggunakan fiber, perbandingan campuran catalyst dan resin adalah $1: 45$, dimana 225 liter resin maka catalyst yang digunakan adalah 5 liter

d. Untuk proses pengecatan dasar, perbandingan campuran cat antara cat dasar dengan hardener adalah $4: 1$ dan clear dengan hardener adalah 4:1.

\section{Daftar Pustaka}

1. Adhitya, M., et al. Devepolment model of synchromesh mechanism to optimization transmission's electric vehicle. in 31st International Electric Vehicle Symposium and Exhibition, EVS 2018 and International Electric Vehicle Technology Conference 2018, EVTeC 2018. 2018.

2. Hidayat, T., N. Nazaruddin, and S. Syafri, Perancangan dan Analisis Statik Chassis Kendaraan Shell Eco Marathon Tipe Urban Concept. 2017, Riau University.

3. Efendi, Z., Perancangan Dan Pembuatan Mekanisme Kerja Pengangkat Bak Pada Model Dump Truck Dengan Menggunakan Sistem Pneumatik. 2007, Fakultas Teknik Universitas Riau.

4. Nazaruddin, N., et al., Analisis Kinerja Sistem Transmisi Pada Mobil Hemat Energi Tipe Hybrid. 2018.

5. Heryana, G., et al. Plug in hybrid electric vehicle power consumption analysis in tropical area. in AIP Conference Proceedings. 2020. AIP Publishing LLC. 
6. Gunawan, K. and N. Nazaruddin, Perancangan dan Pembuatan Komponen Undercarriage pada Model Excavator di Laboratorium Hidraulik dan Pneumatik Universits Riau. Riau University.

7. Suhandi, A. and N. Nazaruddin, Modifikasi Serta Pengujian Sistem Control dan Sistem Swing Model Excavator. Riau University.

8. Nazaruddin, N., et al. Mode Shape Analysis of EV-Bus Chassis with Reverse Engineering Method. in IOP Conference Series: Materials Science and Engineering. 2019. IOP Publishing.

9. Nazaruddin, N., et al. Electric power steering: an overview of dynamics equation and how it's developed for large vehicle. in IOP Conference Series: Materials Science and Engineering. 2019. IOP Publishing.

10. CAR, P.C.T.-R., PERANCANGAN SUSPENSI DEPAN PROTOTIPE CAMPAGNA T-REX CAR.

11. Milliken, W.F., D.L. Milliken, and M. Olley, Chassis design: principles and analysis. Vol. 400. 2002: Society of Automotive Engineers Warrendale, PA.

12. Crolla, D., Automotive engineering: powertrain, chassis system and vehicle body. 2009.

13. Sularso, S., Kiyokatsu, Dasar Perencanaan dan Pemilihan Elemen Mesin, PT. Pradnya Paramita, Jakarta, 1978.

14. Niemann, G., Machine elements design and calculation in mechanical engineering. vol. 1, fundamentals, connections, bearings, shafts and accessories. 2017.

15. Heryana, G. and M.A. Amat. Pengaruh Geometri Lasan pada Plat Aluminium AA1100 Terhadap Sifat Mekanik Lasan Dengan Menggunakan Micro Friction Stir Spot Welding $(\mu F S S W)$. in Prosiding Seminar Nasional Teknik Mesin: Renewable Energy, Automation and CEA Technology. 2019. 